\title{
Engineering Forest Trees with Heavy Metal Resistance Genes
}

\author{
By S. A. MERKLE ${ }^{*}$ \\ Warnell School of Forestry and Natural Resources, University of Georgia, Athens, GA 30602 USA
}

(Received: August 21, 2006/Accepted: October 21, 2006)

\begin{abstract}
Pollution of soil and water with heavy metals such as mercury, cadmium and arsenic, is a worldwide problem. Phytoremediation, the use of plants to remove, sequester or detoxify pollutants, including heavy metals, offers an environmentally-friendly alternative to engineering-based methods for remediation. Forest trees have multiple features that make them particularly useful for removal of toxic heavy metals, especially if they can be engineered with genes allowing them to handle high levels of these elements. Although still in its infancy, research with transgenic trees carrying genes allowing them to detoxify or sequester some heavy metals has already made promising progress. Most of the work to date has been performed using poplar species and hybrids, although other woody species could be equally as useful. Trees have been engineered with genes for the handling of mercury, cadmium, copper and arsenic following two main approaches, phytoextraction and phytotransformation/phytovolatilizaton. In vitro studies have shown the transgenic trees to have enhanced abilities to tolerate and/or accumulate these metals, and preliminary results from field tests indicate that the trees are functioning. New combinations of genes involved in metal transport or conversion may further enhance the heavy metal remediation capabilities of the transgenic trees. Given the environmentally friendly application, forest trees engineered for phytoremediation may be some of the first transgenic forest trees approved for operational deployment.
\end{abstract}

Key words: phytoremediation, gene transfer, heavy metals, pollution, hardwood trees, genetic engineering, transgenic tree, bioremediation, poplar, willow.

\section{Introduction}

For over a century, mining, industrial, agriculture, municipal and defense processes have contributed to wide-spread contamination of soil and water with toxic metals, including arsenic (As), cadmium (Cd), chromium $(\mathrm{Cr})$, copper $(\mathrm{Cu})$, mercury $(\mathrm{Hg})$, nickel $(\mathrm{Ni})$, lead $(\mathrm{Pb})$, selenium (Se) and zinc (Zn). This metal pollution threatens the health of millions of people worldwide. For example, in the United States, $\mathrm{Hg}$ is a common pollutant at government production sites, where it is used in energy- and defense-related activities. Thousands of square miles of land, rivers, lakes and estuaries are contaminated with millions of kilograms of mercury. Methylmercury, produced by bacteria in contaminated aquatic areas, is particularly toxic. Because it is quickly biomagnified in the food chain, it has a devastating impact on humans and other animals (MEAGHER, 2000). Another common pollutant in the U.S. and worldwide is

*) Corresponding author: Scott A. MerkLE. Phone: 706-542-6112. Fax: 706-542-8356. Email: merkle@warnell.uga.edu
As, a naturally occurring element widely distributed on the earth's crust. In the environment, arsenic combines with oxygen, chlorine, and sulfur to form inorganic arsenic compounds. These extremely toxic metalloids, classified as "group A" human carcinogens, cause skin lesions, lung, kidney and liver cancer, and damage to the nervous system (DHANKHER et al., 2002). Cd has been widely dispersed into the general environment and human foodstuffs by agricultural uses of phosphate fertilizers and sewage sludge, as well as by industrial uses of the metal. It has been linked to increased risk of bone fracture, cancer, kidney disfunction and hypertension (SATARUG et al., 2003).

Metal pollutants are particularly difficult to clean up from soil and water, since, unlike organic pollutants, which can be mineralized to harmless small molecules, metals are elements, and thus are immutable by any biochemical reaction (MEAGHER, 2000). Conventional procedures for cleaning up heavy metal-contaminated sites (i.e. excavation and reburial, capping, dredging, electrolytic extraction, chemical leaching) all have problems of expense and disruption of the natural environment. An alternative to these engineering-based remediation approaches is the use of plants to remove pollutants from soil and water through their root systems and detoxify or sequester them, an approach known as phytoremediation. Plants have several properties making them highly suitable for environmental remediation. Since they are autotrophic, plants absorb nearly all of their elemental nutrients directly from the environment, using their roots, which, along with root hairs, constitute a massive surface area through which metals can be extracted from the soil (MEAGHER and HEaton, 2005). Plants also stabilize the soil, preventing erosion, and return fixed carbon into the soil, which supports the proliferation of soil bacteria and fungi, which may also be critical for effective remediation. Once taken up, plants may sequester the pollutants in their tissues (phytoextraction), convert them to less toxic forms (phytotransformation), and/or release them into the atmosphere (phytovolatilization).

A small group of plants, known as hyperaccumulators, can naturally take up and sequester normally toxic amounts of metals, tolerating tissue concentrations up to 1000 -fold higher than non-accumulating plants. Some of these species, the majority of which are from the family Brassicaceae, have been studied for years. Thlaspi caerulescens, for example, can accumulate up to $3 \% \mathrm{dw}$ $\mathrm{Zn}$ and over $1 \% \mathrm{dw} \mathrm{Cd}$ and $\mathrm{Ni}$ (RoBINSON et al., 1998). Alyssum lesbiacum rapidly accumulates $\mathrm{Ni}$ to over $3 \%$ $\mathrm{dw}$ of above-ground tissues (KRAMER et al., 1996). The bulk of these metal-hyperaccumulating plants are char- 
acterized by low biomass production, making them unsuitable for most phytoremediation applications, although a few that produce significant biomass have been described. For example, Brassica juncea (Indian mustard) accumulates lower foliar concentrations of metal than T. caerulescens, but its greater biomass actually results in higher total amounts of metal removal (RoBInson et al., 1998). Another notable exception is the brake fern (Pteris vittata), a plant of significant biomass that accumulated over $1.5 \% \mathrm{dw}$ arsenic when grown on arsenic-spiked soil for two weeks (MA et al., 2001). However, in general, the combination of high metal concentrating ability with high biomass accumulation is relatively rare.

\section{Forest trees as hyperaccumulators}

If some fast-growing forest trees were capable of hyperaccumulating metals, they would make excellent candidates for phytoremediation. A number of forest trees are characterized by very rapid biomass production. Many trees also have extensive, penetrating root systems along with high rates of water uptake and transpiration, giving them the potential to rapidly move metal ions out of the rhizosphere and up the transpiration stream into above-ground tissues. Trees of the genus Populus, in particular, have been singled out as highly suitable candidates for phytoremediation, as argued by Dix et al. (1997). Poplars are in general easy to establish and grow quickly. Their high transpiration rates and wide-spreading root systems make them ideal to intercept, absorb, degrade and/or detoxify contaminants, while reducing soil erosion. Many Populus species, in particular the cottonwoods, are especially adapted for growth on riparian sites, making them a good choice for establishment on sites requiring remediation. Finally, poplar plantings can be maintained by coppicing, helping to maintain sustained root vigor. Poplars have already been tested by some groups for phytoremediation applications. Hybrid poplars tested in buffer strips adjacent to municipal sewage lagoon treatment systems responded well to diluted wastewater, exhibiting a $187 \%$ increase in height and a $1200 \%$ increase in dry mass production in comparison to control trees (Licht, 1990). NEWMAN et al. (1997) reported that Populus trichocarpa $\mathrm{x} P$. deltoides hybrids took up trichloroethylene and degraded it to carbon dioxide and other non-toxic metabolites. Populus deltoides x $P$. nigra hybrid rooted cuttings were demonstrated to take up, hydrolyze and dealkylate the pesticide atrazine to less toxic metabolites (BURKEN and SCHNOOR, 1997). With regard to metal phytoremediation, KOHLER et al. (2004) characterized six metallothionein genes from a $P$. trichocharpa x P. deltoides hybrid, which conferred Cd tolerance when heterologously expressed in a Cd-hypersensitive yeast mutant. However, $P$. deltoides $\mathrm{x} P$. nigra seedlings showed no special ability to hyperaccumulate $\mathrm{Cd}, \mathrm{Ni}, \mathrm{Pb}, \mathrm{Cu}, \mathrm{Fe}, \mathrm{Mn}$ or $\mathrm{Zn}$ when grown on sewage sludge-treated soil, even when the soil was treated with EDTA (LIPHADZI et al., 2003).

The related genus Salix also has many desirable features for phytoremediation. In fact, willows have already been tested in Europe for several years as filters for municipal wastewater (PERTTU and KowALIC, 1997; RIDDELL-BLACK et al., 1995). Early studies indicated that the rates at which willows removes these metals from soil and water may be too slow to make them practical for remediation (RIDDELL-BLACK et al., 1995; FELIX, 1997) and that heavy metals tended to accumulate in the roots of the tested willow clones, rather than being transported to the stems (LANDBERG and GREGER, 1996). Results from more recent studies in which several willow genotypes and varieties were grown on soil contaminated with a variety of heavy metals from long-term sewage sludge disposal, as well as with hydroponics, were more promising. These studies identified a group of willow clones with good survival and biomass production that accumulated relatively higher levels of $\mathrm{Cd}$ and $\mathrm{Zn}$ in the wood, and relatively lower levels of $\mathrm{Ni}$ and $\mathrm{Cu}$ in the bark, while another, less metal-tolerant group, tended to have higher concentrations of $\mathrm{Cu}$ and $\mathrm{Ni}$ in the bark (PUlFORD et al., 2002; WATSON et al., 2003). However, the trees could not be said to have "hyperaccumulated" the metals, since even the highest concentrations of metals in the assayed wood and bark biomass were below $0.1 \%$ and the amounts of the metals taken up by the biomass per hectare were very small in relation to the soil content. Thus, while willows may be a good choice as "filters" for lightly-contaminated water and soil, their ability to handle heavy metals will need to be improved if they are to be used operationally for remediation of heavily contaminated sites.

\section{Engineering forest trees for metal hyperaccumulation}

An alternative approach to finding high-biomass producing plants (i.e. trees) with natural capabilities to accumulate high concentrations of metals is to genetically engineer fast-growing forest trees with foreign genes that allow them to hyperaccumulate metals or to handle them in other ways. There are a handful of examples where just this approach is being tested, and while still in its infancy, preliminary results indicate that forest trees may be engineered to thrive on and detoxify a variety of heavy metals on polluted sites.

\section{Engineering for cadmium and copper hyperaccumulation}

As discussed earlier, hybrid poplars have shown no natural ability to take up and sequester high concentrations of metals. However, in addition to all of the useful features of Populus for phytoremediation listed above, several members of the genus are amenable to in vitro propagation and genetic engineering (CONFALONIERI et al., 2003), making these trees suitable targets for enhanced phytoremediation ability via transgenic technology (unfortunately, there has been no report of the regeneration of a transgenic willow tree to date). A substantial amount of research has already been reported on the performance of grey poplar ( $P$. tremula $\mathrm{x} P$. alba) trees engineered to overexpress a bacterial gene for $\gamma$-glutamylcysteine synthetase ( $\gamma$-ECS). Studies of the overexpression of this gene in plants are based on the 


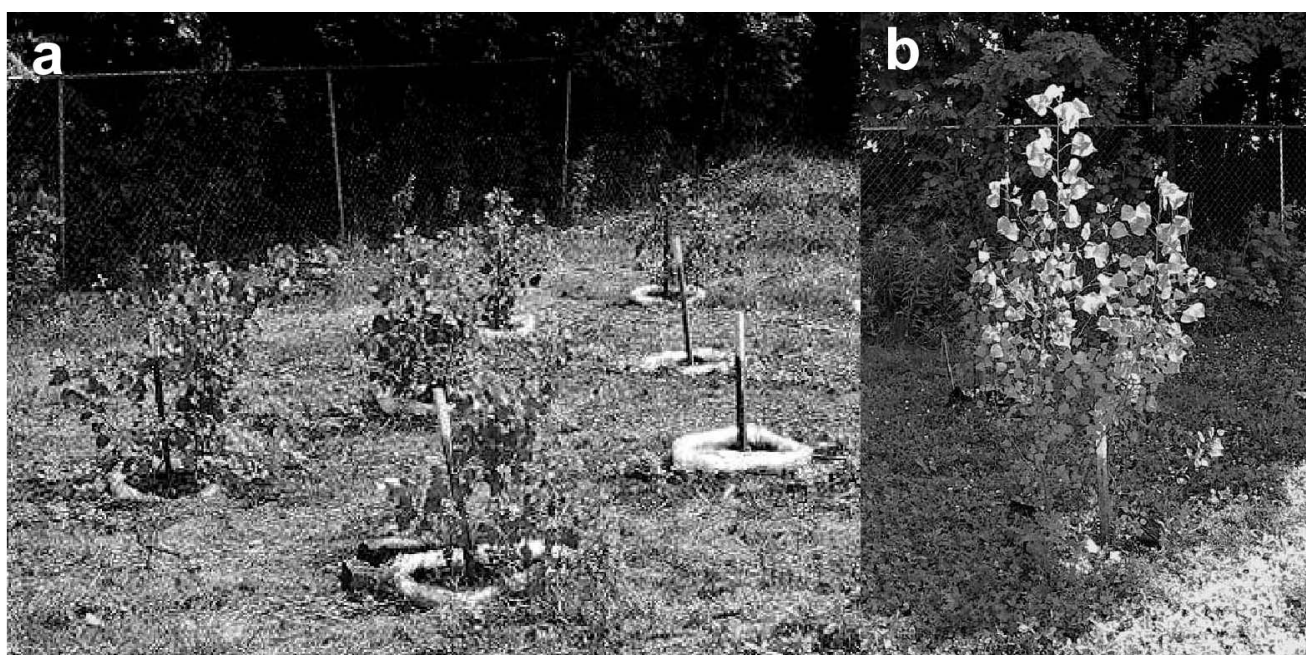

Figure 1. - Transgenic merA eastern cottonwood trees planted on the mercury-contaminated site of an abandoned hat factory in Danbury, CT, USA, immediately following planting (a) and during the second season of growth (b). Photos courtesy of A.C.P. Heaton.

central role played by $\gamma$-ECS in the synthesis of glutathione (GSH), which is in turn a precursor of phytochelatins (PCs). PCs are members of a family of peptides with the general structure ( $\gamma$-Glu-Cys) $)_{n}$-Gly, where $\mathrm{n}=2$ to 11 . These peptides contain a high percentage of Cys sulfhydryl residues, which bind and sequester heavy-metal ions in stable complexes (ZHU et al., 1999). Three enzymes constitute the phytochelatin biosynthetic pathway: $\gamma$-ECS, glutathione synthetase (GS) and phytochelatin synthetase (PS). $\gamma$-Glutamylcysteine synthetase produces $\gamma$-EC dipeptides for subsequent synthesis of phytochelatins, and is believed to be limiting step for both GSH and PCs production in the absence of heavy metals (NоCTOR et al., 1998). Poplars transformed to overexpress $\gamma$-ECS contained higher levels of GSH and $\gamma$-EC than wild-type trees (NOCTOR et al., 1998), with higher levels of GSH found in the phloem of the transgenic trees (HERSCHBACH et al., 1998). Transgenic poplars overexpressing $\gamma$-ECS accumulated more $\mathrm{Cd}$ in their roots than wild-type or transgenic poplars overexpressing GS, when exposed to $\mathrm{CdCl}_{2}$ in hydroponics. When grown in soil containing $2 \mathrm{mM} \mathrm{Cd}$, transgenic poplars overexpressing $\gamma$-ECS in the cytosol and chloroplasts accumulated 2.5 to 3 times higher concentrations of $\mathrm{Cd}$ in their young leaves than did the wild-type trees (KoPRIVOva et al., 2002). One transgenic line overexpressing $\gamma$-ECS in the cytosol is currently being tested in comparison to wild-type trees in the field on sites characterized as low (22-84 ppm), medium (146-384 ppm) or high (1650-4038 ppm) in $\mathrm{Cu}$ contamination due to $\mathrm{Cu}$ mining (Peuke and RenNenberg, 2005a). Preliminary results from the field tests indicated that there were no significant differences in $\mathrm{Cu}$ concentration in shoots of wild-type versus transgenic trees on the sites with low contamination, but on highly contaminated sites, $\mathrm{Cu}$ levels in the transgenic poplars were double those in the wild-type trees (PEUKE and RENNENBERG, 2005a; 2005b).

\section{Engineering for mercury phytoremediation}

Bacteria living in mercury-contaminated environments have evolved resistance to the metal via the mer operon (SUMmers, 1986). Two genes in this operon, merA and merB, encode mercury processing enzymes. The mer $B$ product is an organomercury lyase, which catalyzes the cleavage of the carbon-mercury bond in methylmercury. Mercuric ion, $\mathrm{Hg}(\mathrm{II})$, the product of this reaction, is in turn reduced to elemental mercury, $\mathrm{Hg}(0)$ by mercuric ion reductase, the product of merA. These reactions lower the relative toxicity of the metal by orders of magnitude and allow it to be volatilized from the system (HEATon et al., 1998). Following a demonstration that a modified merA gene conferred mercuric ion resistance to Arabidopsis plants (RUGH et al., 1996), embryogenic regeneration (MERKLE et al., 1990) and biolistic gene transfer (WILDE et al., 1992) systems previously developed for the fast-growing forest tree yellowpoplar (Liriodendron tulipifera) were employed to generate yellow-poplar trees expressing a modified merA gene (RUGH et al., 1998). Yellow-poplar proembryogenic masses (PEMs) were transformed with three modified merA constructs via microprojectile bombardment. Since the wild-type merA gene was isolated from Escherichia coli, each construct was synthesized to have altered flanking regions with stepwise increases [0\% (wild-type), 9\%, and $18 \%$ blocks] of modified coding sequence designed to enhance expression in plants. All the tested merA constructs conferred resistance to toxic, ionic mercury that had been incorporated into the tissue culture medium, as confirmed by tests with both PEMs and germinating somatic embryos. Yellow-poplar somatic embryos containing the most modified merA gene (merA18) germinated to produce somatic seedlings that grew vigorously in media containing a normally toxic level $(50 \mu \mathrm{M})$ of ionic mercury. A mercury volatilization assay showed that the merA18 plantlets released elemental mercury at approximately ten times the rate of untransformed control plantlets, indicating that they efficiently reduced mercuric ion to the elemental form. While the work with yellow-poplar demonstrated the potential to engineer a forest tree with mercury-handling genes, the species is not adapted to growing on the wet soils or riparian sites where mercury contamination is a major problem. 
Therefore, these trees were never tested outside of in vitro conditions.

One forest species that is well-adapted to wet soils and riparian sites is eastern cottonwood (Populus deltoides). While eastern cottonwood has a reputation of being more problematic than other poplar species and hybrids to transform and regenerate, some genotypes can be manipulated to produce transgenic trees (HAN et al., 2000). Using eastern cottonwood clone C175, a genotype previously shown to be amenable to transformation (DINUs et al., 1995), an Agrobacterium-mediated leaf disk transformation system was used to regenerate transgenic eastern cottonwood trees expressing modified merA9 and merA18 genes. Leaf sections from transgenic plantlets produced adventitious shoots in the presence of $50 \mu \mathrm{M} \mathrm{Hg}(\mathrm{II})$, supplied as $\mathrm{HgCl}_{2}$, which completely inhibited shoot induction from leaf explants of wild-type plantlets. Transgenic shoots cultured in medium containing $25 \mu \mathrm{M} \mathrm{Hg}$ (II) showed normal growth and rooted, while wild-type shoots were killed. When the transgenic cottonwood plantlets were exposed to mercuric ion, they evolved 2-4 times the amount of $\mathrm{Hg}(0)$ relative to wildtype plantlets. Transgenic merA9 trees tested in a Georgia Piedmont soil contaminated with $\sim 400$ ppm $\mathrm{Hg}$ (II) showed growth indistinguishable from that in uncontaminated soil, while control plantlets were completely defoliated and dead within a week following potting (CHE et al., 2003).

Trees of one merA eastern cottonwood clone, along with wild-type control trees (approximately 200 trees total) were planted on a mercury-contaminated site which was formerly the location of a hat-making factory in Danbury, CN in June 2003 (IVRY, 2004). Both merA and control trees grew well on the site (Fig. 1). Leaves were sampled from merA and control trees in fall 2004, and analysis of these leaves indicated that those from the merA trees contained one-third to one-half the amount of $\mathrm{Hg}$ as leaves from the control trees (R. B. Meagher and A. C. P. Heaton, Genetics Department, University of Georgia, unpublished data). This result would be expected since the merA trees produce and volatilize $\mathrm{Hg}(0)$, which is then able to leave the plants as a vapor, while the control trees are unable to do so.

Methylmercury $(\mathrm{MeHg}$ ), produced by native bacteria at mercury-contaminated wetland sites, is even more toxic than mercuric ion. Because it is efficiently biomagnified up the food chain, it poses the most immediate threat to animal and human populations. Following work performed in Arabidopsis (BIZILY et al., 1999), eastern cottonwood was engineered with a bacterial merB gene, which converts $\mathrm{MeHg}$ to $\mathrm{Hg}$ (II). Transgenic shoots expressed the MerB protein and demonstrated their resistance to the methylmercury analog phenylmercuric acetate (PMA) by producing longer adventitious roots and higher fresh weights than control shoots cultured on rooting medium supplemented with 2 or 5 $\mu \mathrm{M}$ PMA (CHE et al., 2006). However, in order to remove organic mercury from a contaminated site, it is desirable to have trees expressing both the merA and mer $B$ genes, so that organic mercury compounds can ultimately be converted to the least toxic form, elemental mercury.
Results with Arabidopsis indicated that combining the merA gene with the mer $B$ gene in the same plant can increase the ability of the transgenic plants to grow on levels of organic mercury up to 50-fold higher than wildtype plants and up to 10-fold higher than plants engineered with merB alone (BIZILY et al., 2000). This enhanced resistance to organic mercury is probably due to the fact that plants expressing both the merA and mer $B$ genes together are able to transform both organic and ionic mercury to volatile $\mathrm{Hg}(0)$. To engineer both genes into eastern cottonwood, leaf disks from merA cottonwood trees were re-transformed with the mer $B$ gene. In vitro rooting assays demonstrated that the merA/merB cottonwood trees were highly resistant to PMA relative to wild-type, merA or mer $B$ cottonwood controls. Mercury volatilization assays demonstrated that the merA/merB cottonwoods growing with their roots in medium with PMA evolved elemental mercury vapor two to three times faster than any of the controls, indicating that the mer $A / B$ trees could efficiently convert PMA to $\mathrm{Hg}(0)$ (LYYRA et al., in press).

\section{Engineering trees for arsenic phytoremediation}

Using similar in vitro culture and gene transfer methods to those employed with merA and merB, a bacterial $\gamma$-glutamyl synthetase $(\gamma$-ECS) gene was engineered into eastern cottonwood. A month after being cultured on medium supplemented with $800 \mu \mathrm{M}$ arsenate, leaf sections from $\gamma$-ECS transgenic lines remained green and began to develop callus, while the leaf sections from wild-type plantlets showed no evidence of callus and appeared chlorotic. After 30 days on medium containing $800 \mu \mathrm{M}$ arsenate, wild-type adventitious shoots did not form roots and their leaves appeared chlorotic while $\gamma$-ECS shoots appeared similar to those maintained on medium with no arsenate, and adventitious roots began to appear on these shoots 21 days after initial culture (A. LimA and S. A. MerkLE, unpublished data). Despite the apparent slight enhancement of arsenate resistance conferred to the eastern cottonwood trees by the $\gamma$-ECS gene, work with transgenic $\gamma$-ECS Arabidopsis plants indicated that they removed only slightly more arsenic from the medium than wild-type control plantlets (DHANKHer et al., 2002). Thus, it is unlikely that engineering plants with this gene alone will be useful for removing arsenic from contaminated soil or water. Recent research in which the $\gamma$-ECS gene was combined with other arsenic handling genes, such as arsenate reductase $(\operatorname{ars} C)$, in transgenic Arabidopsis plants indicates that some of these multi-gene approaches have promise (DHANkHER et al., 2002). These same gene combinations can be engineered into eastern cottonwood and other trees and test the potential of these trees for arsenic remediation.

\section{Ethical and social considerations}

Trees genetically engineered for phytoremediation of heavy metals are subject to the same ecological, ethical and societal considerations as other transgenic trees with regard to concerns such as potential for transgene escape, weediness, impact on other organisms, etc. 
(Mullin and Bertrand, 1998). However, in addition to these concerns, the special purposes for which these trees are genetically modified will almost certainly have effects on their eventual deployment and acceptance by the general public. One criticism of the use of genetically engineered trees to concentrate or volatilize heavy metals is that they will not truly resolve the contamination problem, but merely move it around. For example, trees that sequester heavy metals in their leaves will eventually drop the leaves, which, unless they are collected and hauled off the site, will decay, returning the metals to the soil. Tissues of trees expressing merA should not accumulate significant $\mathrm{Hg}$, but it is not yet known if $\mathrm{Hg}$ vapor volatilized from the trees on a heavily contaminated site may rise to unhealthy concentrations in the atmosphere immediately adjacent to the site. However, it should be kept in mind that such concerns regarding the safe disposal or dispersal of contaminants apply to any heavy metal remediation strategy, since the elemental metals themselves are immutable. Thus, as is the case with any remediation approach, such questions regarding how the products from trees that sequester or otherwise process metals will be handled are legitimate and will ultimately require contributions from engineers, civic planners and others to resolve.

Even given these special concerns, it is possible that some of the first transgenic trees approved for operational deployment (in the U.S., at least) will be those engineered for phytoremediation, for a number of reasons. First, since trees engineered to handle pollutants are not intended to be grown to maturity for wood products, they can do their jobs and be removed from the site without ever being allowed to flower, greatly reducing chances of transgene flow to wild relatives. If longer periods of treatment are called for, poplars and most other hardwoods that might be deployed for this purpose can simply be cut off and allowed to coppice so that the new stems can continue the remediation task. Second, results with some plants engineered to handle heavy metals indicate that they are in general less vigorous, and therefore less fit than their wild-type counterparts, especially on substrates lacking in the particular metal they are engineered to handle (RUGH et al., 1996). Thus, at least for some of these trees, concerns that they will become aggressive weeds should be minimal. Finally, public perception of trees designed to help clean up contamination has been largely positive. For example, the merA cottonwood trees planted in Danbury, CT, mentioned earlier, were welcomed by the city administration, which otherwise would have had to spend over $\$ 500,000$ to excavate, remove and replace the contaminated soil (IVRY, 2004). However, the situation may be very different in Europe. For example, in Germany, legislation on the deployment of genetically modified plants has already slowed or even halted progress toward the use of such plants for phytoremediation (PEUKE and RENNENBERG, 2005b).

As indicated in the present overview, results with trees engineered with heavy metal handling genes are still very preliminary, especially with regard to their performance in the field. As results from these tests and tests of new combinations of metal-handling genes in trees become available over the next few years, the true potential of transgenic trees to contribute to this environmentally friendly technology will become clear.

\section{Acknowlegements}

I would like to thank Rich MeAGHER and ANDREW HEATON for their assistance with the manuscript.

\section{Literature cited}

Bizily, S. P., C. L. Rugh, A. O. Summers and R. B. Meagher (1999): Phytoremediation of methylmercury pollution: $m e r B$ expression in Arabidopsis thaliana confers resistance to organomercurials. Proc. Natl. Acad. Sci. USA 96: 6808-6813.

Bizily, S. P., C. L. Rugh and R. B. Meagher (2000): Phytodetoxification of hazardous organomercurials by genetically engineered plants. Nature Biotech. 18: 213-217.

BuRken, J. G. and J. L. Schnoor (1997): Phytoremediation: uptake of atrazine and the role of root exudates. J. Environ. Eng. 122: 958-963.

Che, D., R. B. Meagher, A .C. P. Heaton, A. Lima, C. L. RUGH and S. A. Merkle (2003): Expression of mercuric ion reductase in eastern cottonwood confers mercuric ion reduction and resistance. Plant Biotechnol. J. 1: 311-319.

Che, D. S., R. B. Meagher, C. L. Rugh, T. Kim, A. C. P. HEATON and S. A. MERKLE (2006): Expression of organomercurial lyase in eastern cottonwood enhances organomercury resistance. In Vitro Cell. Dev. Biol. 42: 228-234.

Confalonieri, M., A. Balestrazzi, S. Bisoffi and D. CarBONERA (2003): In vitro culture and genetic engineering of Populus spp.: synergy for forest tree improvement. Plant Cell Tiss. Org. Cult. 72: 109-138.

Dhanker, O. P., Y. J. Li, B. P. Rosen, J. Shi, D. Salt, J. F. Senecoff, N. A. Sashti and R. B. Meagher (2002): Engineering tolerance and hyperaccumulation of arsenic in plants by combining arsenate reductase and gamma-glutamylcysteine synthetase expression. Nature Biotech. 20: 1140-1145.

Dinus, R. J., C. J. Stephens and S. Chang (1995): Agrobacterium tumefaciens-mediated transformation of Populus deltoides leaf sections, pp. 210-219 in Proceedings of the $23^{\text {rd }}$ Southern Forest Tree Improvement Conference, June 22-23, 1995, Asheville, NC.

Dix, M. E., N. B. Klopfenstein, J.-W. Zhang, S. W. WorkMAN and M.-S. KIM (1997): Potential use of Populus for phytoremediation of environmental pollution in riparian zones, pp. 206-211 in Micropropagation, Genetic Engineering and Molecular Biology of Populus, edited by N. B. Klopfenstein, Y. W. Chun, M.-S. Kim and M. R. AHuja, USDA Forest Service General Technical Report RM-GTR-297.

FELIX, H. (1997): Field trials for in-situ decontamination of heavy-metal polluted soils using crops of metal-accumulating plants. Zeitschrift Fur Pflanzenernahrung Und Bodenkunde 160: 525-529.

Han, K. H., R. Meilan, C. Ma and S. H. Strauss (2000): An Agrobacterium tumefaciens transformation protocol effective on a variety of cottonwood hybrids (genus Populus). Plant Cell Rep. 19: 315-320. 
Heaton, A. C. P., C. L. Rugh, N. Wang and R. B. Meagher (1998): Phytoremediation of mercury- and methylmercury-polluted soils using genetically engineered plants. J. Soil Contam. 7: 497-509.

Herschbach, C., E. van Der Zalm, A. Schneider, L. Jouanin, L. J. DE KoK and H. Rennenberg (2000): Regulation of sulfur nutrition in wild-type and transgenic poplar overexpressing $\gamma$-glutamylcysteine synthetase in the cytosol as affected by atmospheric $\mathrm{H}_{2} \mathrm{~S}$. Plant Physiol. 124: 461-473.

IVRY, B. (2004): Uprooting toxic waste, cheaply. Popular Sci. 264: $41-44$.

Kohler, A., D. Blaudez, M. Chalot and F. Martin (2004): Cloning and expression of multiple metallothioneins from hybrid poplar. New Phytol. 164: 83-93.

Koprivova, A., S. Kopriva, D. JAger, B. Will, L. JouAnin and H. RenNenBerg (2002): Evaluation of transgenic poplars over-expressing enzymes of glutathione synthesis for phytoremediation of cadmium. Plant Biol. 4: 664-670.

Kramer, U, J. D. Cotter-Howells, J. M. ChaRnock, A. J. M. BAKER and J. A. C. SMITH (1996): Free histidine as a metal chelator in plants that accumulate nickel. Nature 379: 635-638.

LANDBERG, T. and M. GREGER (1996): Differences in uptake and tolerance to heavy-metals in Salix from unpolluted and polluted areas. Applied Geochemistry 11: $175-180$.

Licht, L. A. (1990): Poplar tree buffer strips grown in riparian zones for biomass production and non-point source pollution control. Ph.D. dissertation, University of Iowa.

LiPhadZI, M. S., M. B. KiRkHaM, K. R. Mankin and G. M. PAULSEN (2003): EDTA-assisted heavy-metal uptake by poplar and sunflower grown at a long-term sewagesludge farm. Plant Soil 257: 171-182.

Lyyra, S., R. B. Meagher, T. R. Kim, A. C. P. Heaton and S. A. Merkle: Co-expression of mercuric ion reductase and organomercury lyase in eastern cottonwood or detoxification of organomercurials (Plant Biotechnol J. (in press)).

Ma, L. Q., K. M. Komar, C. Tu, W. Zhang, Y. CAI and E. D. KenNELLy (2001): A fern that hyperaccumulates arsenic. Nature 409: 579.

MeAGHER, R. B. (2000): Phytoremediation of toxic elemental and organic pollutants. Curr. Opinion Plant Biol. 3: 153-162.

Meagher, R. B. and A. C. P. Heaton (2005): Strategies for the engineered phytoremediation of toxic element pollution: mercury and arsenic. J. Ind. Microbiol. Biotechnol. 32: 502-513.

Merkle, S. A., R. J. Sotak, A. T. WiEcko and H. E. SomMER (1990): Maturation and conversion of Liriodendron tulipifera somatic embryos. In Vitro Cell. Dev. Biol. 26: 1086-1093.

Mullin, T. J. and S. BERTRAND (1998): Environmental release of transgenic trees in Canada - potential benefits and assessment of biosafety. Forestry Chronicle 74: 203-219.
Newman, L. A., S. E. Strand, N. Choe, J. Duffy, G. Ekuan, M. Ruszau, B. B. Shurtleff, J. Wilmoth, P. HeILMAN and M. P. Gordon (1997): Uptake and biotransformation of trichloroethylene by hybrid poplars. Environ. Sci. Technol. 31: 1062-1067.

Noctor, G., A. Arisi, L. Jounanin, K. Kuner, H. RennenBERG and C. FOYER (1998): Glutathione biosynthesis: metabolism and relationship to stress tolerance explored in transformed plants. J. Exp. Bot. 49: 623-647.

Perttu, K. L. and P. J. Kowalik (1997): Salix vegetation filter for purification of waters and soils. Biomass \& Bioenergy 12: 9-19.

Peuke, A. D. and H. Rennenberg (2005a): Phytoremediation with transgenic trees. Z. Naturforsch. 60: 199-207.

Peuke, A. D. and H. Rennenberg (2005b): Phytoremediation. EMBO Rep. 6: 497-501.

Pulford, I. D., D. Riddell-Black and C. Stewart (2002): Heavy metal uptake by willow clones from sewage sludge-treated soil: the potential for phytoremediation. Inter. J. Phytoremed. 4: 59-72.

Riddell-Black, D., C. Rowlands and A. Snelson (1995): Heavy metal uptake from sewage sludge amended soil by Salix and Populus species grown for fuel, pp. 51-52 in Fourteenth Annual Symposium on Current Topics in Plant Biochemistry, Physiology, and Molecular Biology, April 19-22, 1995, Columbia, MO.

Robinson, B. H., M. Leblanc, D. Petit, R. R. Brooks, J. H. KIRKMAN and P. E. H. GREGG (1998): The potential of Thlaspi caerulescens for phytoremediation of contaminated soils. Plant Soil 203: 47-56.

Rugh, C. L., H. D. Wilde, N. M. Stack, D. M. Thompson, A. O. Summers and R. B. Meagher (1996): Mercuric ion reduction and resistance in transgenic Arabidopsis thaliana plants expressing a modified bacterial merA gene. Proc. Natl. Acad. Sci. USA 93: 3192-3187.

Rugh, C. L., J. F. Senecoff, R. B. Meagher and S. A. MERKLe (1998): Development of transgenic yellow poplar for mercury phytoremediation. Nature Biotechnol. 10: 925-928.

Satarug, S., J. R. Baker, S. URbenjapol, M. HaswellElkins, P. E. B. ReIley, D. J. Willliams and M. R. Moor (2003): A global perspective on cadmium pollution and toxicity in non-occupationally exposed population. Toxicol. Lett. 137: 65-83.

SumMERS, A. O. (1986): Organization, expression, and evolution of genes for mercury resistance. Ann. Rev. Microbiol. 40: 607-634.

Watson, C., I. D. Pulford and D. Riddell-Black (2003): Screening of willow species for resistance to heavy metals: comparison of performance on a hydroponics system and field trials. Inter. J. Phytoremed. 5: 351-365.

Wilde, H. D., R. B. Meagher and S. A. Merkle (1992): Expression of foreign genes in transgenic yellow-poplar plants. Plant Physiol. 98: 114-120.

ZHU, Y. L., E. A. H. PILON-Smits, L. JouAnin and N. Terry (1999): Overexpression of glutathione synthetase on Indian mustard enhances cadmium accumulation and tolerance. Plant Physiol. 119: 73-80. 